\title{
DIAGNOSTIC ROLE OF ULTRASONOGRAPHY IN ACUTE APPENDICITIS
}

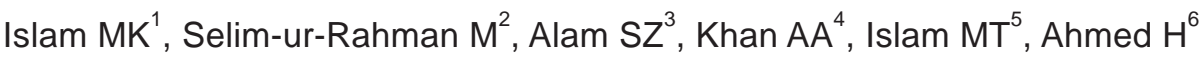

\begin{abstract}
Introduction: Abdominal Ultrasonography (USG) is the most commonly used method for diagnosing acute appendicitis the most common surgical cause of acute abdomen. In this study, we observed the reliability of USG for diagnosing acute appendicitis.
\end{abstract}

Objectives: To evaluate the role of ultrasonography in the diagnosis of acute appendicitis.

Methods: In this study, we performed abdominal USG of 100 patients admitted with lower right abdominal pain and diagnosed as acute surgical abdomen according to the physical examination and laboratory findings. These patients were surgically treated by appendecectomy, and excised specimens were sent for histopathological examination.

Results: One hundred patients were assessed in this study. Out of them $82.0 \%$ patients had acute appendicitis and diameter of their appendices were more or equal to $6 \mathrm{~mm}$. Twenty nine percent of the patients were below 21 years of age. Intraluminal fluid was present in $81 \%$ of patients and peri-appendicular fluid was present in $66.7 \%$ of patients. Leucocytosis was present in $49 \%$ of the cases and neutrophilia in $84 \%$ of the cases. All of the patients presented with lower abdominal pain with migration of pain in $52 \%$ cases and they had right iliac fossa tenderness. The sensitivity, specificity, Positive Predictive Value (PPV), Negative Predictive Value (NPV) and accuracy rate of ultrasonography was $76.8 \%, 88.9 \%, 96.9 \%$, $45.7 \%$ and $79.0 \%$, respectively.
Conclusion: Acute appendicitis is a common indication for emergency abdominal surgery. Proper clinical assessment is the mainstay of diagnosis in acute appendicitis and addition of routine abdominal ultrasound by graded compression technique can improve the diagnostic accuracy and adverse outcome.

Key-words: USG, Acute Appendicitis.

\section{Introduction}

Appendicitis results from an acute inflammation of the appendix and creates the most common abdominal surgical emergency ${ }^{1}$. It occurs in $7 \%$ to $12 \%$ of the general population and although it may occur at any age, it is most common in 10 to 19 years old age group $(233 / 100,000$ population annually $)^{2}$. Physicians from a wide range of medical specialties including internal medicine and paediatrics, as well as surgeons, encounter patients with this condition in their daily practice. When it presents with typical symptoms, it is relatively easy to diagnose ${ }^{3}$. Usually, the diagnosis of appendicitis can be ellusive and fraught with pitfalls because of the absence of a pathgnomonic sign or symptom. The rate of unnecessary laparotomies is still high.To balance an acceptable positive laparotomy rate with minimal delayed or missed diagnoses, the clinician must take into account all the available historical and physical findings, laboratory data and appropriate imaging method $^{4}$. The rate of negative appendectomy is reported to be between $20 \%$ and $30 \%$. To reduce the rate of negative appendectomy and to improve the sensitivity of the diagnosis this method of graded

1. Lt Col Md. Khairul Islam, MBBS, FCPS, Classified Specialist in Radiology, BG Hospital, Peelkhana, Dhaka;

2. Lt Col Md. Selim-ur-Rahman, MBBS, MS, Classified Orthopedic Surgeon, CMH, Bogra; 3. Col Syed Zoherul Alam, MBBS, MCPS, FCPS, Classified Specialist in Radiology, CMH, Dhaka; 4. Col Arif Ahmed Khan, MBBS, MCPS, FCPS, Classified Specialist in Pathology, AFIP, Dhaka; 5. Maj Md.Tarikul Islam, MBBS, Graded Specialist in Surgery, AFMI, Dhaka; 6. Dr. Hussain Ahmed, MBBS, DMRD, Junior Consultant in Radiology, BG Hospital. Peelkhana, Dhaka. 
compression sonography is well established by several large prospective trials that have reported sensitivities of $77-89 \%$ and specificities of 94-96\%. In all of these prospective studies, evaluations were performed directly by radiologists who often had subspecialty training in sonography; thus, these results may only be a guide in estimating the actual values in an average community hospital with a general radiologist performing and interpreting the examination ${ }^{5}$. The primary aim of this study was to evaluate the diagnostic accuracy, sensitivity and specificity of sonography in the evaluation of acute appendicitis.

\section{Materials and Methods}

This study was conducted in Combined Military Hospital, Bogra over a period of about 2 years from April 2011 to February 2013. A total of 100 clinically suspected patients of acute appendicitis were taken as study group. They were evaluated by clinical examination, relevant laboratory investigations and abdominal USG and subsequent histopathological examination. All the patients who presented with pain in right lower abdomen, patients with appendicular masses who were managed initially conservatively and later underwent interval appendisectomy and patients with recurrent appendicitis were included in this study. Patients with chronic infectious diseases like ileo-caecal tuberculosis, neoplasm of appendix were excluded from this study. During clinical examination low grade fever, pain in right iliac fossa, Mcburney's sign, rebound tenderness were observed. For relevant laboratory investigation complete blood count (CBC) and urine R/E were done. Ultrasound was performed by the graded compression technique. The sonographic diagnosis was based on presence of an enlarged non-compressible appendix, outer wall to inner wall diameter of more than $6 \mathrm{~mm}$, presence of a complex mass or presence of dilated bowel loops in the right iliac fossa and eliciting localized tenderness ${ }^{6}$.

Sixty five cases were found sonographically positive. Out of 65 cases, during operation 63 patients showed signs of acute appendicitis and 2 were normal. Histopathologically 63 cases were confirmed as appendicitis. Among the sonographycally negative 35 patients, 21 cases were operated for appendicitis on clinical basis and 16 cases showed appendicitis on biopsy. In rest 14 cases, 8 cases did not improve clinically and subsequently underwent surgery and biopsy confirmed 4 cases as appendicitis. Rest 6 sonographycally negative patients were discharged as they improved clinically but subsequently again admitted due to recurrence of symptoms and emergency operation were done and 3 cases were confirmed as appendicitis in subsequent biopsy.

Cases declared positive for appendicitis on histopathology were taken as true positive, and those declared positive for appendicitis on sonography but not confirmed on histology were taken as false positive. Similarly, cases declared normal on sonography and histopathology were taken as true negative, and those reported normal on sonography but proven otherwise on biopsy were taken as false negative. Data were analyzed by simple statistical method (percentage) and presented in the form of frequency distribution using Statistical Package for the Social Sciences (SPSS) 15.0 for Windows.

\section{Results}

Table-I shows distribution of patients by age. Most of the patients (29.0\%) were in age group 11-20 years followed by $24.0 \%, 21.0 \%, 17.0 \%$ and $09.0 \%$ in age groups $21-30$ years, 31-40 years, $\leq 10$ years and $\geq 40$ years respectively.

Table-I: Distribution of patients by age $(n=100)$.

\begin{tabular}{|l|c|c|}
\hline Age(yrs) & Frequency & Percentage \\
\hline$\leq 10$ & 17 & 17.0 \\
\hline $11-20$ & 29 & 29.0 \\
\hline $21-30$ & 24 & 24.0 \\
\hline $31-40$ & 21 & 21.0 \\
\hline$\geq 40$ & 09 & 9.0 \\
\hline
\end{tabular}

Table-Il shows signs and symptoms of the patients. The entire group of patients had lower abdominal pain with migration of pain in $52 \%$ cases. Vomiting \& fever were present in $40 \%$ \& $37 \%$ of patients respectively. Same percentage of patients had right iliac fossa tenderness with rebound tendernessin in $68 \%$ cases. Rovesign's sign were positive in $50 \%$ of these patients. Forty nine percent $\& 84 \%$ of patients had leucocytosis \& neutrophilia respectively. 
Table-II: Clinical signs and symptoms of the patients $(n=100)$.

\begin{tabular}{|c|c|c|c|}
\hline & Sign / Symptoms & Frequency & Percentage \\
\hline \multirow{6}{*}{$\frac{\mathscr{c}}{\sigma}$} & Pain in lower abdomen & 100 & 100.0 \\
\hline & Migration of pain & 52 & 52.0 \\
\hline & Vomiting & 40 & 40.0 \\
\hline & Fever & 37 & 37.0 \\
\hline & Dysuria & 02 & 2.0 \\
\hline & Diarrhoea & 01 & 1.0 \\
\hline \multirow{8}{*}{ 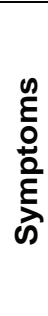 } & Right iliac fossa tenderness & 100 & 100.0 \\
\hline & Rebound tenderness & 68 & 68.0 \\
\hline & Guarding & 28 & 28.0 \\
\hline & Tachycardia & 82 & 82.0 \\
\hline & Rovesing's sign & 50 & 50.0 \\
\hline & Leucocytosis & 49 & 49.0 \\
\hline & Neutrophilia & 84 & 84.0 \\
\hline & Urine R/E -Pus cells & 06 & 06.0 \\
\hline
\end{tabular}

Table-III shows the ultrasonographic findings of these patients. All of the patients who had appendicitis, diameter of their appendixes were more or equal to $6 \mathrm{~mm}$. Intraluminal fluid was present in $81 \%$ patients. None of the patients had compressibility. Caecal wall thickening was $<5 \mathrm{~mm}$ in $54.0 \%$ patients and $\geq 5 \mathrm{~mm}$ in $46.0 \%$ patients. Periappendicular fluid was present in $66.7 \%$ patients and appendicolith was present in $4.8 \%$ patients. Out of all cases 65 were diagnosed as appendicitis by USG and among them 63 were confirmed by histopathological evaluation. They were true positive. Two cases were diagnosed as having appendicitis by USG but not confirmed by histopathological findings; that was false positive. Out of 35 sonographically negative cases, 23 cases were confirmed as appendicitis and 12 were non-appendicitis by histopathological findings; they

Table-III: Ultrasonographic findings of the patients $(n=63)$.

\begin{tabular}{|l|c|c|c|}
\hline Characteristics & Status & Frequency & Percentage \\
\hline Diameter of appendix & $<6 \mathrm{~mm}$ & 0 & 0.0 \\
\cline { 2 - 4 } & $\geq 6 \mathrm{~mm}$ & 63 & 100.0 \\
\hline \multirow{2}{*}{ Intraluminal fluid } & Present & 51 & 81.0 \\
\cline { 2 - 4 } & Absent & 12 & 19.0 \\
\hline \multirow{2}{*}{ Compressibility } & Present & 0 & 0.0 \\
\cline { 2 - 4 } & Absent & 63 & 100.0 \\
\hline \multirow{2}{*}{ Cecal wall thickening } & $<5 \mathrm{~mm}$ & 34 & 54.0 \\
\cline { 2 - 4 } & $\geq 5 \mathrm{~mm}$ & 29 & 46.0 \\
\hline \multirow{2}{*}{ Periappendicular fluid } & Present & 42 & 66.7 \\
\cline { 2 - 4 } & Absent & 21 & 33.3 \\
\hline \multirow{2}{*}{ Appendicolith } & Present & 3 & 4.8 \\
\cline { 2 - 4 } & Absent & 60 & 95.2 \\
\hline
\end{tabular}

Table-IV: Comparison of USG with histopathology in diagnosis of acute appendicitis.

\begin{tabular}{|l|c|c|c|}
\hline \multirow{2}{*}{ USG } & \multicolumn{2}{|c|}{ Histopathology } & \multirow{2}{*}{ Total } \\
\cline { 2 - 3 } & Appendicitis & Non-appendicitis & \\
\hline Appendicitis & $63(73.3)$ & $2(14.3)$ & $65(65.0)$ \\
\hline Non-appendicitis & $23(26.7)$ & $12(85.7)$ & $35(35.0)$ \\
\hline Total & $86(100.0)$ & $14(100.0)$ & $100(100.0)$ \\
\hline
\end{tabular}

were false negative and true negative respectively. Sensitivity, specificity, positive predictive value, negative predictive value and accuracy of the USG in the diagnosis of appendicitis were $77.80 \%$, $96.80 \%, 87.50 \%, 93.80 \%$ and $92.50 \%$ respectively (Table-V).

Table-V: Validity test $(n=100)$.

\begin{tabular}{|l|c|c|}
\hline Validity Test & Value (\%) & $95 \% \mathbf{C l}$ \\
\hline Sensitivity & 77.80 & $47.00-88.30$ \\
\hline Specificity & 96.80 & $87.90-99.80$ \\
\hline PPV (Positive predictive value) & 87.50 & $52.90-99.30$ \\
\hline NPV (Negative predictive value) & 93.80 & $85.10-96.70$ \\
\hline Accuracy & 92.50 & $78.70-97.20$ \\
\hline
\end{tabular}

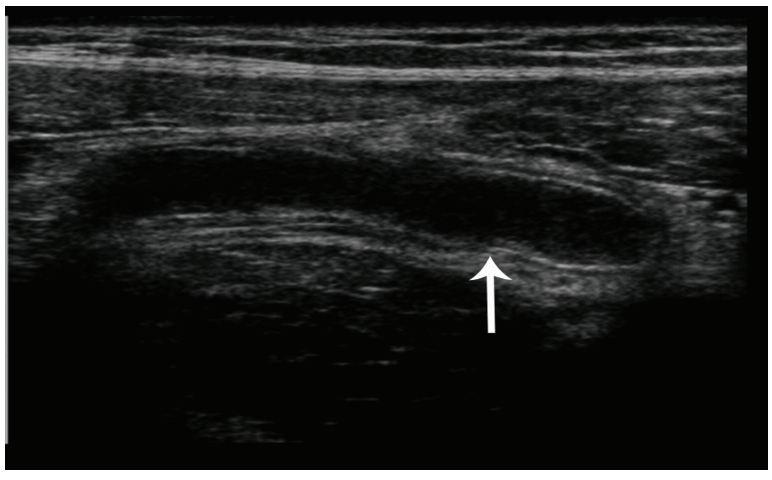

Fig-1: Periappendicular collection in section.

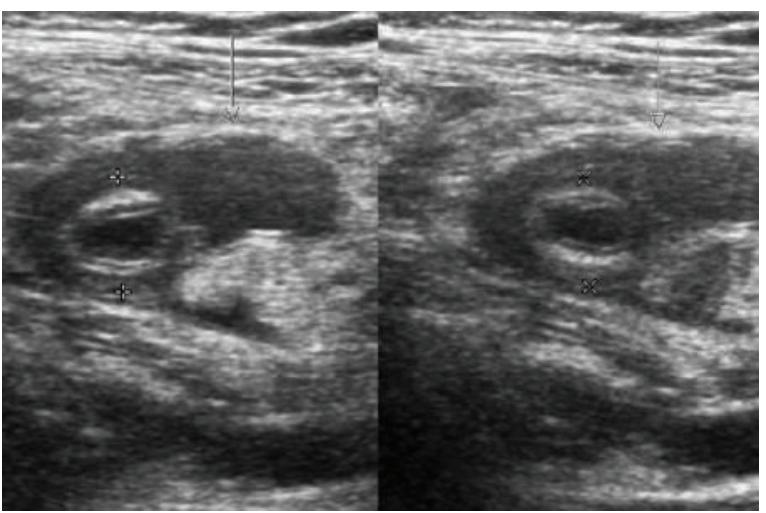

Fig-2: Acute appendicitis. 


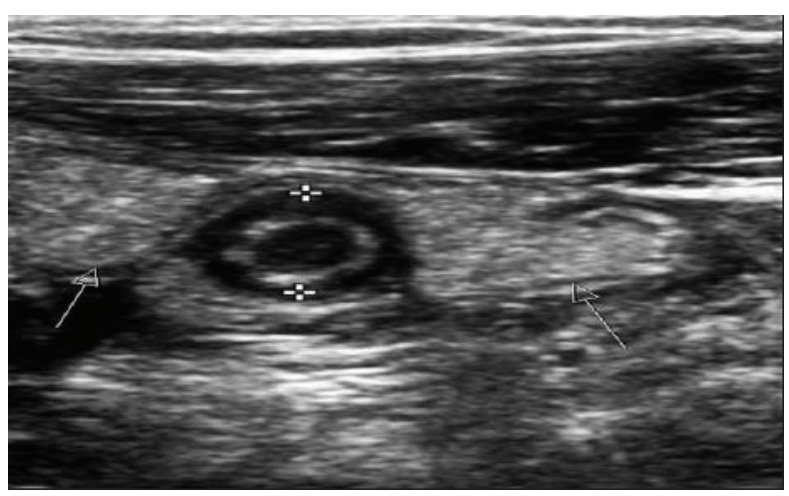

Fig-3: Thick wall of Inflammed appendix in cross sectional image.

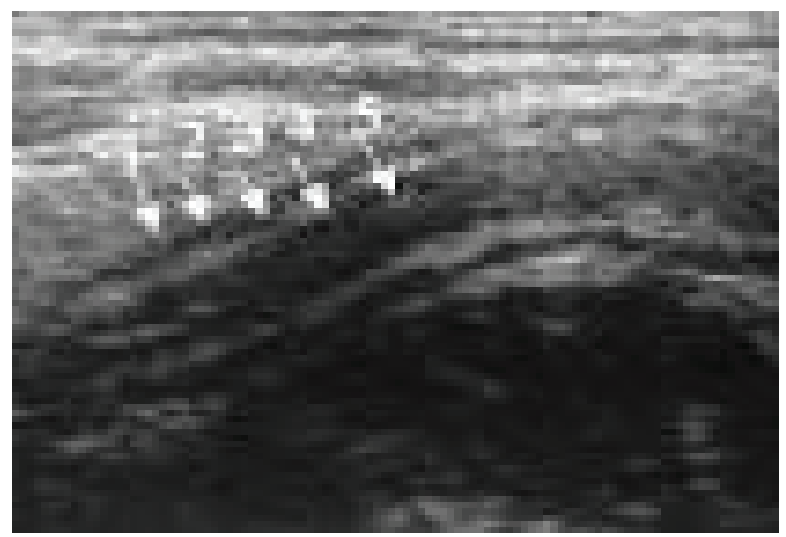

Fig-4: Intraluminal fluid (5) in acutely Inflammed appendix.

\section{Discussion}

In recent years, ultrasonography has achieved an important place in the diagnosis of acute appendicitis. Tenderness in right iliac fossa was present in almost all cases. Rebound tenderness, guarding and Rovesing's sign if present, are more specific for acute appendicitis. These findings tallied with the findings of the study by Tauro LF et al ${ }^{7}$. In this study leucocytosis was present in $75 \%$ of the cases and neutrophilia in $86 \%$ of the cases.

A study of 225 patients by Doraiswamy ${ }^{8}$ showed leucocytosis in $42 \%$ and neutrophilia in $96 \%$ of the cases. Several cross sectional imaging studies demonstrated that outer diameters of acutely inflammed appendices were not less than $6 \mathrm{~mm}^{9,10}$, which is almost similar with the present study. In our study, we found that maximum patients were below the age of 21 years and vomiting was present in $40 \%$ patients, leukocytosis in $49 \%$ of patients. Drinković $\mathrm{N}$ stated $^{11}$ that appendicitis is most common in the age group of 11 to 20 years and the frequency of the studied symptoms (vomiting, leukocytosis) range from $49.4 \%$ to $64.8 \%$.
The overall sensitivity, specificity, PPV, NPV and accuracy were found to be $77.80 \%, 96.80 \%$, $87.50 \%, 93.80 \%$ and $92.50 \%$ respectively, which showed that USG has a high sensitivity and specificity in diagnosing appendicitis. The overall sensitivity and specificity rates were almost same with the values drawn by Tauro et $\mathrm{al}^{7}$, Douglas et $\mathrm{al}^{12}$, Saeed et $\mathrm{al}^{13}$ and Nasiri et $\mathrm{al}^{14}$, whose sensitivity values varied from $71.2 \%-94.7 \%$ and specificity ranges varied from $83.3 \%-88.9 \%$.

\section{Conclusion}

Acute appendicitis is one of the most common acute surgical conditions of the abdomen. The diagnostic accuracy is significantly high, if the clinical signs and symptoms are combined with USG findings. The overall sensitivity of abdominal USG in the diagnosis of acute appendicitis was $77.80 \%$ and specificity was $96.80 \%$. Although ultrasound is a simple, cost-effective, non-invasive investigation with high acceptance by the patients, clinical examination remains a corner stone of the diagnosis of acute appendicitis. We recommend USG as a valuable tool in diagnosing acute appendicitis in spite of prevalence of expensive investigations like CT abdomen and laparoscopy; thus, reducing the cost of treatment and preventing negative laparotomies.

\section{References}

1. Appendicitis Imaging [on line]. available at http://emedicine.medscape.com/article/363818-ove rview (accessed January 2014).

2. Addiss DG, Shaffer N, Fowler BS. The epidemiology of appendicitis and appendectomy in the United States. Am J Epidemiol 1990; 132:910-25.

3. Bari MR, Al-Azad S, Chowdhury N. Role of Ultrasonography in the Diagnosis of Appendicitis with Peroperative and Histopathological Correlation. Bangladesh Journal of Radiology and Imaging 2009; 17(1):10-4.

5. Chan I, Bicknell SB, Graham M. Utility and Diagnostic Accuracy of Sonography in Detecting Appendicitis in a Community Hospital. AJR 2005; 184:1809-12. 
6. Ramachandran P, Suit CJ, Newman KD. Role of ultrasonography in diagnosis of acute appendicitis. J Pediat Surg 1996; 31:164-7.

7. Tauro LF, Premanand TS, Aithala PS, George C Suresh HB, Acharya D, John P. Ultrasongraphy is still a useful diagnostic tool in acute appendicitis. Journal of clinical and diagnostic research 2009;3(5):1731-6.

8. Doraiswamy N.V. Leucocyte counts in the diagnosis and prognosis of acute appendicitis in children. Br J Surg 1979; 66:782.

9. Jeffrey RB Jr, Laing FC, Townsend RR. Acute appendicitis: sonographic criteria based on 250 cases. Radiology 1988; 167:327-9.

10. Vignault $F$, Filiatrault $D$, Brandt $M L$, Garel $L$, Grignon A, Oulmet A. Acute appendicitis in children: evaluation with US. Radiology 1990; 76:5014.
11. Drinković N. Age distribution and clinical characteristics in acute appendicitis. Vojnosanit Pregl, Military-medical and pharmaceutical review 1991 Mar-Apr;48(2):115-9.

12. Douglas CD, Macpherson NE, Davidson PM. Randomised controlled trial of ultrasonography in diagnosis of acute appendicitis, incorporating the Alvarado score. BMJ 2000;321:1-7.

13. Saeed K, Mehboob F, Azam V.Role of abdominal sonography in the diagnosis of acute appendicitis.RMJ 2009;34(2):138-40.

14. Nasiri S, Mohebbi F, Sodagari N. Diagnostic values of ultrasound and the Modified Alvarado Scoring System in acute appendicitis. International Journal of Emergency Medicine 2012, 5:26. 